Bioscientia Medicina: Journal of Biomedicine \& Translational Research

Journal Homepage: www.bioscmed.com

\title{
The Role of Serum Omega 3 Levels on Muscle Mass, Muscle Strength, and Physical Performance in the Elderly Community
}

Welly Salutondok ${ }^{1^{*}}$, Nur Riviati ${ }^{1}$, Yulianto kusnadi ${ }^{1}$, Erial Bahar $^{2}$, Nova Kuniati ${ }^{1}$, Syamsu Indra $^{1}$

${ }^{1}$ Department of Internal Medicine, Faculty of Medicine, Universitas Sriwijaya, Palembang, Indonesia

${ }^{2}$ Department of Anatomy, Faculty of Medicine, Universitas Sriwijaya, Palembang, Indonesia

\section{A R T I C L E I N F O \\ Keywords: \\ Advanced age \\ Omega-3 \\ Muscle mass \\ Muscle strength \\ Physical performance \\ RSMH Palembang \\ Corresponding author: \\ Welly Salutondok \\ E-mail address: wellysalutondok13@gmail.com}

All authors have reviewed and approved the final version of the manuscript.

https://doi.org/10.32539/bsm.v5i3.220

\begin{abstract}
A B S T R A C T
Background. Old age is related to geriatric syndrome where there are several health problems that often occur related to a decrease in body function and an increase in the inflammatory process. Decrease in muscle mass, muscle strength and physical performance will lead to a condition of sarcopenia and frailty syndrome in the elderly. The importance of prevention so that sarcopenia does not occur in the elderly by evaluating the factors that can cause it, one of which is controlling nutritional factors (macro and micro nutrients), such as in research, namely omega-3 macronutrients. The purpose of this study was to determine the correlation between serum omega-3 levels with muscle mass, muscle strength, and physical performance in the elderly community at Moehammad Hoesin Hospital Palembang. Methods. This research is an observational analytic study with a cross-sectional approach which was conducted at the Integrated Geriatric Clinic Internal Medicine RSMH Palembang from November 2019 to November 2020. A sample of 21 people aged $>60$ years was examined for muscle mass, muscle strength, physical performance and omegalevels. 3 serums. All data processing and analysis in this study used SPSS version 25 for Windows. Results. Of the 21 subjects, it was found that women were 19 people $(90.5 \%)$ and 2 men $(9.5 \%)$. The mean value of muscle mass was $37.65 \pm 5.7$, hand grip strength was $24.04 \pm 5 \mathrm{~kg}$, and walking speed was $6.72 \pm 1.8$ seconds per 6 meters. There were 11 subjects with low serum omega-3 levels of $485.25 \pm 110.19$ mg. There was a significant relationship between serum omega-3 levels and muscle mass $(p=0.041)$ with moderate correlation strength $(r=0.448)$. Conclusion: Muscle mass has a significant relationship with serum omega-3 levels in the elderly with moderate strength. Meanwhile, muscle strength and physical performance did not have a significant relationship.
\end{abstract}

\section{Introduction}

Govinda (PERGEMI, 2015) states that old age is not a disease but an advanced stage of a life process characterized by a decrease in the body's ability to adapt to environmental stress. The Ministers of Health, including the Regional Office for South-East Asia (SEARO) at the 30th Health Ministers Meeting agreed to raise the issue of aging as a priority health problem called the Yogyakarta Declaration on Aging and Health 2012.1-3 Old age is related to geriatric syndrome where there are several health problems that often occur, these signs indicate a decline in body function in the elderly which is the impact of lifestyle and previous disease history. Signs of geriatric syndrome include decreased muscle function, muscle mass, bone mass, osteoporosis, easy falls, weight loss, dementia, lack of sleep, bladder disorders, delirium, decreased organ function and body immunity. ${ }^{4}$ Decreased muscle mass occurs $0.47 \%$ in men and $0.37 \%$ in women per year, at 
the age of 75 there was a decrease in muscle mass by $0.80 \%-0.98 \%$ in men and $0.64 \%-0.70 \%$ in women per year. $5,6,7$

Changes in human muscle mass in the elderly were first reported in the late 1980s. Since then studies on the reduction of muscle mass, bone mass, muscle function have continued to be developed and the concept of sarcopenia was born. The initial methods used to detect decreased muscle mass, bone mass and muscle function were tomography and MRI (including using anthropometric measurements), then developed by examinations using other methods such as ultrasound, bioimpedance analysis and dual-energy $X$ ray absorptiometry to calculate regionally the total muscle mass in the body. ${ }^{5}$ Evaluation of sarcopenia and illustrations related to old age can be seen through signs of decreased muscle mass, muscle function, physical performance. 5

Decreased body function in the elderly will result in problems with movement disorders and function of the elderly. Elderly people experience decreased walking function, decreased balance function, decreased functional ability, decreased independence in activities of daily life. Factors that affect changes in the decrease in body muscle mass and size, such as the amount of fat mass, race, genetic factors, physical activity, body hormones and nutritional intake. ${ }^{5}$

On the 23rd day of old age, the Ministry of Communication and Information Technology of the Republic of Indonesia in collaboration with the Indonesian Ministry of Health plans to develop programs for the elderly with the aim of making old age independent and prosperous. One of the programs that will be carried out is rehabilitation for the elderly to improve functional abilities, mobility and activities to meet the needs of the elderly including self-care. ${ }^{8}$

One of the strategies that can be achieved to prevent and reduce and delay the decline in musculoskeletal function in the elderly can be done through improving nutritional intake. ${ }^{9}$ Dietary fat is a part of nutritional macronutrients that plays a role in the formation of muscle structure and function. Fatty acids act as the main substance for the production of ATP so that they can provide the main source of energy during physical activity such as exercise, as well as being the main structural component of sarcolemma (muscle cell membrane). ${ }^{10}$ Omega-3 and omega- 6 are unsaturated fatty acids (Poly Unsaturated Fatty Acid (PUFA)) which has an important role in musculoskeletal health.11-13 PUFA induces antioxidant-oxidant balance, preventing oxidative stress that can cause atrophy in skeletal muscles. ${ }^{12-14}$

Omega-3 fatty acids are known to exert beneficial health effects on a number of biological processes such as enhancing immune profiles, optimizing cognitive enhancement, and neuromuscular function. ${ }^{15}$ Recent studies have shown a strong positive correlation between omega-3 fatty acid intake and skeletal muscle mass. ${ }^{16}$ Consistently Jeromsol et al (2018) also show that clinically there is an increase in muscle mass and strength in those aged 65 years and over and intake of omega-3 and prevent a decrease in mitochondrial respiration. 17

McGlorry et al (2019) found an effective way to optimize omega-3 fatty acid intake, namely through the incorporation of eicosapentaenoic acid (EPA; 20: 5n - 3) and docosahexaenoic acid (DHA; 22: 6n - 3) into the phospholipid membrane of the sarcolemma and intracellularly. . In their observations, McGlorry et al found that there was an increase in muscle mass and strength in the elderly who consumed omega-3 fats with EPA and DHA, and there was a decrease in inflammation and increased body immunity. ${ }^{15}$ In general, omega-3s can provide a protective effect on bones and muscles while omega-3 - 6 is thought to have a pro-inflammatory effect with adverse consequences for musculoskeletal health. So, the higher omega-3 content in the body can be especially beneficial for improving muscle health 16

McKee's 2019 study shows populations with a higher omega-3 to omega- 6 ratio in their bodies, such as Japanese or Inuit people, have lower rates of osteoporosis than populations with a lower omega-3 ratio than the omega- 6 ratio. ${ }^{16}$ As we get older, the pattern of life and nutrient intake changes, in most cases the nutritional intake decreases so that the body's macronutrients and micronutrients do not have much reserves. Omega- 3 levels play a role in the anti- 
inflammatory process in the body while omega- 6 plays a pro-inflammatory role. If the body is deficient in omega-3s, it facilitates the inflammatory process and increases levels of Interleukin 6 which can cause sarcopenia. 18

\section{Methods}

This study used an observational analytic design with a cross sectional approach. The target population in this study were all elderly patients in the elderly community of RSMH Palembang. The affordable population is all samples aged $\geq 60$ years who are members of the elderly community of RSMH Palembang. The research subjects were 21 people who met the inclusion criteria. Inclusion criteria were elderly aged $\geq 60$ years, able to communicate well and understandably, willing to participate in research and sign informed consent.

All patients who met the sample inclusion and exclusion criteria and were willing to take part in the study by signing the consent form, were then carried out identification, including: name, age, gender, education and occupation. Anamnesis (autoanamnesis / alloanamnesis) which includes: main complaints, additional complaints, history of disease, and drugs that have been used, history of chronic disease, history of smoking. The history was carried out by the researcher. Physical examination includes height, weight, body mass index, vital sign, Body Impedences Analysis (BIA): BMI, fat mass (FM), free fat mass (FMM), Visceral Fat Analysis (VFA): Waist Circumference (WC), Skeleton Muscle Index (SMI) by researchers. The serum Omega-3 test was measured by immunochemical quantification using the high performance liquid chromatography method which was carried out in Prodia's Laboratory.

Processing and data analysis using the SPSS 25 for Windows program. Data is presented in tables and graphs. The data is tested whether the distribution is normal or not, if the distribution is normal then the Pearson correlation test is used and if the distribution data is not normal, the Spearman correlation test is used.

\section{Results}

Seen from the general characteristics of the research sample in Table 1. the sample was dominated by women as many as 19 people (90.5\%) and 2 (9.5\%) were men. All ages in the study were $>60$ years as many as 21 samples with a mean mean of $64.81(3,829)$ years, the youngest age in this study was 60 years and the oldest was 73 years. The majority of samples had normal body weight of 10 (47.6\%) samples, 4 (19\%) samples each had BMI less and more and 3 (14.3\%) samples were obese. BMI in this study had a mean of 21.34 (2.066).

In Table 2 , it is found that serum omega 3 levels in the blood at the age of the elderly sample get a mean mean of $4.55 \pm 23 \mathrm{pg} / \mathrm{mL}$ in samples with 11 (52.4\%) having low omega-3 levels. It can be seen in Table 4.3 that there are significant levels of omega-3 serum for age and elderly people.

Table 4. presents data on muscle mass, walking time in 6 meters, hand grip strength and PASE calories / week. It was found that the mean muscle mass in the age group $>60$ years was a mean $37.65 \pm 5.7$. The walking duration of the samples> 60 years old was mean $6.72 \pm 1.8$ seconds per 6 meters. The hand grip strength in the elderly> 60 years is $24.04 \pm 5 \mathrm{~kg}$. PASE calories / week at age $>60$ years was $740.3 \pm 192.5$. The results of the $\mathrm{T}$ test showed that there was no significant relationship between age and muscle mass, length of walking, hand grip strength and PASE calories / week.

Table 5. presents data regarding the correlation of omega 3 levels in the blood with muscle mass, muscle strength and physical performance. It can be seen that muscle mass has a significant relationship with serum omega 3 levels $(\mathrm{p}=0.041)$ with moderate correlation strength (0.448). While the length of walking, hand grip strength and PASE calories / week did not have a statistically significant relationship in this study.

Figure 1 above describes the correlation of muscle mass, walking time, hand grip strength and PASE calories / week and it is found that muscle mass has moderate correlation strength ( $\mathrm{r}-0.448)$ while walking time and hand grip strength have weak correlation 
Table 1. General Characteristics of Research Samples

\begin{tabular}{|c|c|c|}
\hline General characteristics & $\mathbf{N}(\%)$ & Mean (SD or range) \\
\hline \multicolumn{3}{|l|}{ Age } \\
\hline$\geq 60$ tahun & 21 (100\%) & $64.81 \%(3.829)$ \\
\hline \multicolumn{3}{|l|}{ Gender } \\
\hline Male & $2(9.5 \%)$ & \\
\hline Female & 19 (90.5\%) & \\
\hline BMI & & 21.34 (2.066) \\
\hline Less & 4 (19\%) & \\
\hline Normal & $10(47.8 \%)$ & \\
\hline \multicolumn{3}{|l|}{ More } \\
\hline \multicolumn{3}{|l|}{ Obesity } \\
\hline \multicolumn{3}{|l|}{ Comorbidity } \\
\hline Nothing & $15(71.4 \%)$ & \\
\hline Hypertension & $3(14.3 \%)$ & \\
\hline Diabetes & $3(14.3 \%)$ & \\
\hline CAD & $3(14.3 \%)$ & \\
\hline
\end{tabular}

Table 2. Omega-3 levels in old age

\begin{tabular}{lcc}
\hline & $\mathbf{N}=\mathbf{2 1}(\%)$ & Mean (SD atau range) \\
\hline Omega-3 level & & $4.55 \pm 23$ \\
Less & $10(47.6 \%)$ & \\
Normal & $11(52.4 \%)$ & \\
\hline
\end{tabular}

Table 3 Correlation of Omega-3 levels with age and BMI in the elderly

\begin{tabular}{lcc}
\hline Variable & Omega-3 (r) & p value \\
\hline Age & -0.511 & $<0.05$ \\
BMI & -0.109 & $<0.05$ \\
\hline
\end{tabular}

* correlation test with Spearman's rho

Table 4. Muscle Mass, Muscle Strength and Physical Performance

\begin{tabular}{lcc}
\hline Variable $(\mathrm{n}=21)$ & Age $\geq 60$ years & $\mathrm{P}$ \\
\hline Muscle Mass & $37.65 \pm 5.7$ & 0.479 \\
Long Walk & $6.72 \pm 1.8$ & 0.800 \\
Hold hand & $24.04 \pm 5$ & 0.570 \\
PASE Calories / Week & $740.3 \pm 192.5$ & 0.839 \\
\hline
\end{tabular}

* Unpaired $\mathrm{T}$ test $\mathrm{p}$ value is significant if $\mathrm{p}<0.05$, normally distributed data are presented with mean $\pm \mathrm{SD}$ 
Table 5 The Relationship Between Omega 3 and Muscle Mass, Muscle Strength and Physical Performance

\begin{tabular}{lcc}
\hline Variable $(\mathrm{n}=21)$ & $\mathrm{R}$ & $\mathrm{O}$ \\
\cline { 2 - 3 } & 0.448 & $0.041^{*}$ \\
\hline Muscle Mass & 0.118 & $0.609^{*}$ \\
Long Walk & 0.142 & $0.540^{*}$ \\
Hold hand & -0.167 & $0.144^{*}$ \\
PASE Calories / Week & \multicolumn{2}{c}{ Ome-3 } \\
\hline
\end{tabular}

* Spearman's rho test, $p$ value is significant if $p<0.05$, the strength of correlation is very weak if $r<0.2$, weak if $r=0.2-0.4$, moderate if $r=0.41-0.6$, strong if $r=0.61-0.8$ and very strong if $r>0.8$
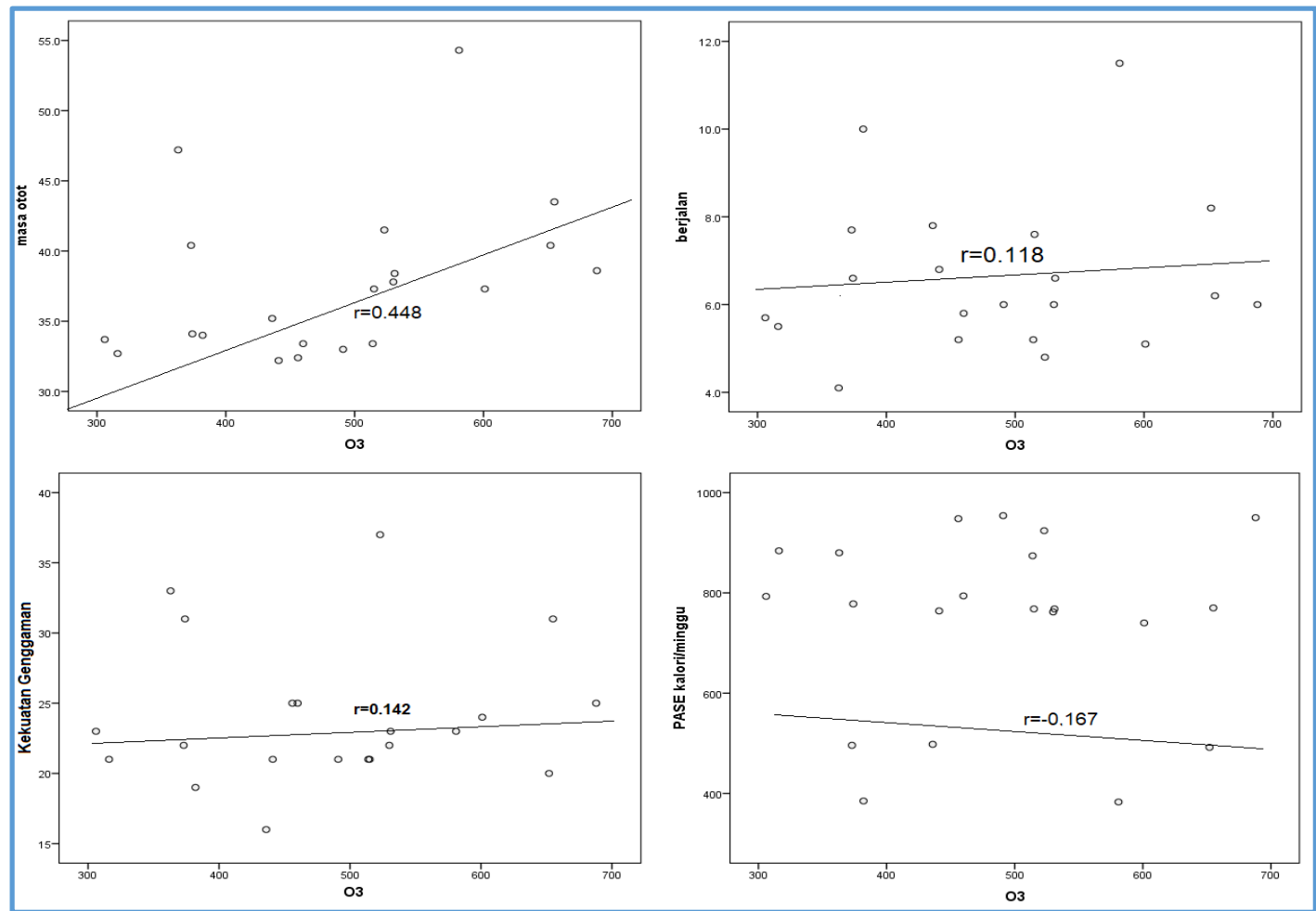

Figure 1. Graph of Correlation between Muscle Mass, Walking Time, Hand Grip Strength, PASE calories / week

\section{Discussion}

In this study, serum omega-3 levels in the elderly sample obtained a mean value of $4.55 \pm 23 \mathrm{pg} / \mathrm{mL}$, the correlation between age and omega-3 was significant (because it was above 0.05) but the correlation was negative $(-0.511)$, where the higher the age, the lower the omega-3 levels. Likewise, the correlation between BMI and omega 3 is significant (because it is above 0.05) but the correlation is negative with weak strength $(-0.109)$

D'Ascoli et al in 2016 concluded that the elderly with omega 3 levels $<500 \mathrm{mg}$ had a 15.4 times risk of experiencing sarcopenia. ${ }^{70}$ Lukaschek et al in 2016 also found that samples with low index omega-3 levels were associated with weak muscle strength, and bodily performance in the elderly. ${ }^{71}$ Another mechanism of action of omega- $3 \mathrm{~s}$ is anabolic effects that are regulated by transcription through activation of the mTOR pathway. The mTOR pathway plays a key role in many cell growth processes, for skeletal muscle formation and muscle protein synthesis.54 Through the downstream regulators 4E-BP1 and S6K1, mTOR regulates muscle protein synthesis. Smith et al. found an increased activation of the mTOR-p70s6k signaling pathway in response to increased amino acid and insulin supply after 8 weeks of omega-3 PUFAs 
compared to the placebo group. 54

Lack of omega-3 fatty acids, caused by insufficient intake or due to diseases that reduce absorption, can inhibit brain development, physical health and environmental interactions, which have a strong effect on the formation of cognitive development. Prolonged omega-3 deficiency can be fatal. Lack of omega-3 fatty acids causes nerve and vision problems and can interfere with the development of the nervous system. As a result, there may be disturbances in the immune system, memory, mental and vision. $48-50$

In this study, the mean muscle mass in the elderly group was a mean of $37.65 \pm 5.7$. The walking duration of the samples> 60 years old was mean $6.72 \pm 1.8$ seconds per 6 meters. The hand grip strength in the elderly group was $27.04 \pm 5 \mathrm{~kg}$. PASE calories / week in the elderly group was $740.3 \pm 192.5$. The results of the $T$ test showed that there was no significant relationship between age and muscle mass, length of walking, hand grip strength and PASE calories / week.

In this study, there was no significant relationship between muscle mass and sarcopenia in the elderly community. Changes in muscle strength with age can be affected by the number and size of muscles that change to atrophy and hypoplasia, a decrease in slow and fast motor units and the presence of atrophy in type I and II muscle fibers. Type II muscle fibers are fast fibers that have a higher glycolytic potential, low oxidative capacity and a faster response than type I (slow fibers). There is a conversion from type II to type I fibers because of the potential adaptive response. In advanced ussia muscles, the decrease in type I and II fibers results in changes in muscle function, especially muscle strength. 19,21

In contrast to this study, Titin in 2019 in his dissertation study on 283 samples aged $>60$ years found that there was a significant relationship between muscle mass and sarcopenia.72 In line with Titin, Pratiwi et al. In 2019 in their library review also concluded that muscle mass is associated with sarcopenia with the conclusion that the aging process causes accumulation of oxidative damage to proteins, DNA, lipid membranes, and cell organelles. The accumulation of damage that occurs in extracellular, intracellular and protein membranes is a basic mechanism of decline in function in the aging process and is one of the biomarkers of aging. Oxidative stress causes accumulated damage in the oxidized cell nucleus and mitochondrial DNA with mitochondrial damage. The accumulated damage due to oxidative stress will continue to increase with the aging process ${ }^{73}$

In this study, there was no significant relationship between physical performance by looking at the mean length of walking and PASE calories / week with the incidence of sarcopenia in the elderly community. In a 2019 study by Biben et al., They found a significant relationship between physical performance such as walking time, hand grip strength and PASE calories / week with sarcopenia $(\mathrm{p}<0.05)$. Low capacity and efficiency of mitochondria is associated with decreased physical performance in old age, but in older people who are still active there is an increase in muscle mass and mitochondrial capacity. ${ }^{74}$ Titin et al in 2019 also found a significant relationship between physical performance such as grip strength, length of time. walking and PASE calories / week with sarcopenia in samples $>60$ years of age. ${ }^{72}$

In this study, it was found that muscle mass had a significant relationship with serum omega 3 levels $(\mathrm{p}=$ 0.041) with moderate correlation strength (0.448). While the length of walking, hand grip strength and PASE calories / week did not have a statistically significant relationship in this study. The dissertation research conducted by Hani in 2019 found a significant relationship with moderate strength correlation between body muscle mass and serum omega 3 levels, but it is slightly different from this study. Hani also found that physical performance and PASE calories / week also had a significant relationship with moderate correlation. 66

There are three hypothetical mechanisms and supporting data regarding the relationship of omega 3 levels in the body to muscle mass and physical performance: anti-inflammatory effects, mammalian targets of rapamycin activation (mTOR) used as examples and reduction of insulin resistance. The antiinflammatory effects of omega-3 PUFAs are generally accepted by the body. A meta-analysis study conducted 
by Custodero et al. confirmed that there was a reduction in $\mathrm{CRP}$ and IL-6 after taking supplementation with omega-3 PUFAs in middle-aged and older adults. 60 Additionally, a 2017 RCT conducted by Daboit et al investigated the effects of EPA and DHA therapy on inflammation in adults. older. Supplementation had a significant decreasing effect on IL-6, IL-1 $\beta$ and TNFa levels after 4 weeks of use and was even greater after 8 weeks. 56

Yoshino et al. found that omega-3 PUFA supplementation induced small but important changes in gene expression, with increased expression of pathways involving regulation of mitochondrial function and decreased expression of the inhibitory pathway on mTOR, thereby supporting skeletal muscle anabolism. ${ }^{61}$ In conclusion, omega-3 PUFAs may aid anabolic coping age-related resistance by increasing the rate of muscle protein synthesis via stimulation of the mTOR signaling pathway. Several studies have shown a role for decreased insulin resistance in response to omega-3 PUFA therapy. 59

\section{Conclusion}

Muscle mass has a significant relationship with serum omega-3 levels in the elderly with moderate strength. Meanwhile, muscle strength and physical performance did not have a significant relationship.

\section{References}

1. World Health Organization (WHO). Article: World Population Aging 2019: HighlightsThe United Nations. 2019. https://www.un.org ivillage' publications 'pdf accessed in December 2019

2. Indonesian Ministry of Health. Article: Indonesia Entering the Aging Population Period. Thursday, 4 July 2019. https://www.depkes.go.id/article/view/19 070500004/indonesia-masuki-periode-

aging-population.html accessed in
December 2019.

3. World Health Organization (WHO). Article: Aging and Health. 5 February 2018. https://www.who.int/news-room/factsheets/detail/ageing-and-health accessed on December 2019.

4. Trevisan K. "Theories of Aging and the Prevalence of Alzheimer's Disease." BioMed Research International 2019.

5. Heymsfield SB. Skeletal muscle mass and quality: evolution of modern measurement concepts in the context of sarcopenia. Proceedings of the Nutrition Society, 2015; 74.4: 355-366.

6. Forbes GB. Longitudinal changes in adult fat-free mass: influence of body weight. Am J Clin Nutr, 1999; 70: 1025-1031.

7. Alexandre Tda S, Duarte YA, Santos JL. Sarcopenia according to the European Working Group on Sarcopenia in Older People (EWGSOP) versus dynapenia as a risk factor for mortality in the elderly. $\mathrm{J}$ Nutr Health Aging, 2014; 18: 751-756.

8. Ministry of Communication and Information of the Republic of Indonesia (Kominfo). Article: Independent and Prosperous $\quad 2019$. https://kominfo.go.id/index.php/content/ detail/19022/lansia-mandiri-

sejahtera/0/artikel_gpr accessed on December 2019.

9. Abdelhamid A. The relationship between omega-3, omega-6 and total polyunsaturated fat and musculoskeletal health and functional status in adults: a systematic review and meta-analysis of RCTs. Calcified tissue international, 2019, 105.4: 353-372.

10. Ethgen O, Beaudart C, Buckinx F, Bruyere O, Reginster JY. The future prevalence of sarcopenia in Europe: a claim for public health action. Calcif Tissue Int, 2016; 100: 229-234

11. Yazar T, Yazar HO. Prevalance of sarcopenia according to decade. Clinical nutrition ESPEN, 2019, 29: 137-141. 
12. Skaaby T, Betina HT, Allan L. "Vitamin D, Sarcopenia and Aging." Vitamin D in Clinical Medicine. Vol. 50. Karger Publishers, 2018. 177-188.

13. Calvani $\mathrm{R}$ "Biomarkers for physical frailty and sarcopenia: state of the science and future developments." Journal of cachexia, sarcopenia and muscle, 2015: (6.4) 278286

14. Bianchi L. "Prevalence and clinical correlates of sarcopenia, identified according to the EWGSOP definition and diagnostic algorithm, in hospitalized older people: The GLISTEN Study." Journals of Gerontology Series A: Biomedical Sciences and Medical Sciences, 2017: (72.11) 15751581.

15. McGlory C, Philip C, Everson AN. "The Influence of Omega-3 Fatty Acids on Skeletal Muscle Protein Turnover in Health and Disease." Frontiers in nutrition 62019 : (6) 144

16. McKee A, John EM. "Hormones and Sarcopenia." Current Opinion in Endocrine and Metabolic Research, 2019.

17. Jeromson S, Mackenzie I, Doherty MK, Whitfield PD, Bell G, Dick J. Lipid remodeling and an altered membrane-associated proteome may drive the differential effects of EPA and DHA treatment on skeletal muscle glucose uptake and protein accretion. Am $J$ Physiol Endocrinol Metab. (2018) 314: E605-19.

18. Inouye SK, Studenski S, Tinetti ME et al. Geriatric syndromes: clinical, research, and policy implications of a core geriatric concept. $J$ Am Geriatr Soc, 2007; 55: 780-91

19. Maddox, George L. The encyclopedia of aging: a comprehensive resource in gerontology and geriatrics. Springer, 2013.

20. Peterson SJ, Mozer M. The differentiation between Srcopenia and Cachexia among cancer patient. Nutriotion in clinical practice, 2017, 32(1):30-39.
21. Manini TM, Gundermann DM, Clarck BC. Aging of The Muscles and Joints. Hazzard's Geriatric Medicine and Gerontology. 7th edition, Chapter 113, 2017; p.1715-37

22. Bischoff-Ferrari HA, Willett WC, Wong JB, Stuck AE, Staehelin HB, Orav EJ. Prevention of nonvertebral fractures with oral vitamin $\mathrm{D}$ and dose dependency: a meta-analysis of randomized controlled trials. Arch Intern Med 2009; 169:551-561.

23. Cruz-Jentoft AJ. "Sarcopenia: revised European consensus on definition and diagnosis." Age and ageing 48.1 (2018): 16-31.

24. Rosenberg IH. Sarcopenia: origins and clinical relevance. J Nutr 1997; 127: 990S-91S

25. Ashton-Miller JA, Alexander NB. Biomechanics of Mobility. Hazzard's Geriatric Medicine and Gerontology. 7th ed, Chapter 114, 2017; p. 1739-53

26. Nugraha A, Munawar AR, Teguh P. "Rancang Bangun Alat Pengukur Persentase Lemak Tubuh Dengan Metode Whole Body Measurement Bioelectrical Impedance Analysis (BIA) Empat Elektroda Berbasis Mikrokontroler ATmega 32." TRANSIENT 2016:(5.2) 157-165.

27. Cruz-Jentoft AJ, et al. "Sarcopenia: European consensus on definition and diagnosisReport of the European Working Group on Sarcopenia in Older PeopleA. Age and ageing 39.4, 2010: 412423.

28. Bian A. A study on relationship between elderly sarcopenia and inflammatory factors IL-6 and TNF-a. European journal of medical research, 2017, 22.1: 25.

29. Bischoff-Ferrari HA, Willett WC, Wong JB, Stuck AE, Staehelin HB, Orav EJ. Prevention of Nonvertebral Fractures with Oral Vitamin D and Dose Dependency: a meta analysis of randomized controlled trials. Arch Intern Med 2009; 169: 551-561

30. Brown JC, Harhay MO, Harhay MN: Sarcopenia and mortality among a population-based 
sample of community-dwelling older adults. J Cachexia Sarcopenia Muscle 2016;7:290-298.

31. Bischoff-Ferrari HA, Willett WC, Orav EJ, Lips P, Meunier PJ, Lyons RA. A pooled analysis of vitamin $D$ dose requirements for fracture prevention. N Engl J Med, 2012;367:40-49

32. Ryall JG, Schertzer JD, Lynch GS. Cellular and molecular mechanisms underlying age-related skeletal muscle wasting and weakness. Biogerontology, 2008; 9:213-228.

33. Dupont J. "The role of omega-3 in the prevention and treatment of sarcopenia." Aging clinical and experimental research, 2019; 1-12.

34. Tessier AJ, Chevalier S. An update on protein, leucine, omega-3 fatty acids, and vitamin D in the prevention and treatment of sarcopenia and functional decline. Nutrients, 2018; 10(8), 1099.

35. Di Girolamo FG, Situlin R, Mazzucco S, Valentini R, Toigo G, Biolo G. Omega-3 fatty acids and protein metabolism: enhancement of anabolic interventions for sarcopenia. Current Opinion in Clinical Nutrition \& Metabolic Care, 2014; 17(2), 145-150.

36. Marzetti E. "The Aging Muscle and Sarcopenia: Interaction with Diet and Nutrition." Molecular Basis of Nutrition and Aging. Academic Press, 2016; p.355-361.

37. Witard OC, Emilie C, Stuart RG. "Long-chain n3 fatty acids as an essential link between musculoskeletal and cardio-metabolic health in older adults." Proceedings of the Nutrition Society, 2019; 1-9.

38. Payette $H$, Roubenoff $R$, Jacques PF. Insulinlike growth factor-1 and interleukin 6 predict sarcopenia in very old community-living men and women: the Framingham Heart Study. $J$ Am Geriatr Soc, 2003; 51:1237-1243

39. Schaap LA, Pluijm SM, Deeg DJ. Inflammatory markers and loss of muscle mass (sarcopenia) and strength. Am J Med, 2006; 119:526.e9526.e 17
40. Baylis D, Bartlett DB, Patel HP.Understanding how we age: insights into inflammaging. Longev Healthspan, 2013; 2:8

41. Bano G, Trevisan C, Carraro S. Inflammation and sarcopenia: a systematic review and metaanalysis. Maturitas, 2017; 96:10-15

42. Karstoft K, Pedersen BK. Skeletal muscle as a gene regulatory endocrine organ. Curr Opin Clin Nutr Metab Care, 2016; 19:270-275

43. Benatti FB, Pedersen BK. Exercise as an antiinflammatory therapy for rheumatic diseasesmyokine regulation. Nat Rev Rheumatol, 2015; $11: 86-97$

44. Schaap LA, Pluijm SM, Deeg DJ. Higher inflammatory marker levels in older persons: associations with 5-year change in muscle mass and muscle strength. J Gerontol A Biol Sci Med Sci, 2009; 64:1183-1189

45. Mets T, Bautmans I, Njemini R. The influence of celecoxib on muscle fatigue resistance and mobility in elderly patients with inflammation. Am J Geriatr Pharmacother, 2004; 2:230-238

46. Trappe TA, Carroll CC, Dickinson JM. Influence of acetaminophen and ibuprofen on skeletal muscle adaptations to resistance exercise in older adults. Am J Physiol Regul Integr Comp Physiol, 2011; ( 300)R655-R662

47. Abdelhamid AS, Brown TJ, Brainard JS et al. Omega-3 fatty acids for the primary and secondary prevention of cardiovascular disease. Cochrane Database Syst Rev 2018. (11) d003177

48. Vannice G, Rasmussen H. Position of the academy of nutrition and dietetics: dietary fatty acids for healthy adults. J Acad Nutr Diet, 2014; 114:136-153

49. Calder PC. Dietary fatty acids and the immune system. Lipids, 1999; (34) S137-S140

50. Burdge GC, Wootton SA. Conversion of alphalinolenic acid to eicosapentaenoic, docosapentaenoic and docosahexaenoic acids in young women. Br J Nutr, 2002; 88:411-420 
51. Papanikolaou Y, Brooks J, Reider C. U.S. adults are not meeting recommended levels for fish and omega-3 fatty acid intake: results of an analysis using observational data from NHANES 2003-2008. Nutr J, 2014; 13:31

52. Sokola-Wysoczanska E, Wysoczanski T, Wagner J. Polyunsaturated fatty acids and their potential therapeutic role in cardiovascular system disorders-a review. Nutrients, 2018; 10:1561

53. Kiecolt-Glaser JK, Epel ES, Belury MA. Omega3 fatty acids, oxidative stress, and leukocyte telomere length: a randomized controlled trial. Brain Behav Immun, 2013; 28:16-24

54. Konagai C, Yanagimoto K, Hayamizu K. Effects of krill oil containing n-3 polyunsaturated fatty acids in phospholipid form on human brain function: a randomized controlled trial in healthy elderly volunteers. Clin Interv Aging. 2013; 8:1247-1257

55. Dangour AD, Allen E, Elbourne D. Effect of 2-y n-3 long-chain polyunsaturated fatty acid supplementation on cognitive function in older people: a randomized, double-blind, controlled trial. Am J Clin Nutr. 2010; 91:1725-1732

56. Gray SR, Mittendorfer B. Fish oil-derived n-3 polyunsaturated fatty acids for the prevention and treatment of sarcopenia. Curr Opin Clin Nutr Metab Care. 2018; 21:104-109

57. Smith GI, Atherton P, Reeds DN. Dietary omega3 fatty acid supplementation increases the rate of muscle protein synthesis in older adults: a randomized controlled trial. Am $J$ Clin Nutr, 2011,93:402-412

58. Smith GI, Julliand S, Reeds DN. Fish oil-derived n-3 PUFA therapy increases muscle mass and function in healthy older adults. Am J Clin Nutr, 2015,102:115-122

59. Da Boit M, Sibson R, Sivasubramaniam S. Sex differences in the effect of fish-oil supplementation on the adaptive response to resistance exercise training in older people: a randomized controlled trial. Am $J$ Clin Nutr, 2017, 105:151-158

60. Custodero C, Mankowski RT, Lee SA. Evidence based nutritional and pharmacological interventions targeting chronic low-grade inflammation in middle-age and older adults: a systematic review and meta-analysis. Ageing Res Rev, 2018,46:42-59

61. Yoshino J, Smith GI, Kelly SC. Effect of dietary n-3 PUFA supplementation on the muscle transcriptome in older adults. Physiol Rep, 2016

62. Boirie Y, Christelle G. "Fast digestive proteins and sarcopenia of aging." Current Opinion in Clinical Nutrition \& Metabolic Care, 2018, (21.1) 37-41.

63. Phaniendra A, Jestadi DB, Periyasamy L. Free radicals: properties, sources, targets, and their implication in various diseases. Indian journal of clinical biochemistry, 2015, 30.1: 11-26.

64. Bakta I. Made. Effect of Omega 3 on Muscle Mass \& 6 Minute Walking Test for the Elderly with COPD and Sarcopenia. 2019.

65. Setiati, Siti. Artikel: "Geriatric Medicine, Sarcopenia, Frailty, and Quality of Life for Elderly Patients: Challenges of the Future of Medical Education, Research and Services in Indonesia. "Indonesian Medical Journal, 2014

66. Chen LK, Liu LK, Woo J. Sarcopenia in Asia: consensus report of the Asian working group for Sarcopenia. J Am Med Dir Assoc. 2014: 28(1):26-29.

67. Seto E, Setiati S, Laksmi PW, Tamin TZ. Uji diagnostik, sistem skor sindroma frailty berdasarkan cardiovascular health study, study of osteoporotic fracture dan indeks frailty berbasis comprehensife geriatric assessement dibandingkan dengan indeks frailty 40 item pada pasien usia lanjut. 2014. Thesis

68. Purnamasari D. Diabetes diagnosis and classification. In: Setiati S, Alwi I, Sudoyo A, Simadibtara M, Setiyohadi B, Syam FA, editors. 
Internal medicine textbook. Edition 6. Jakarta: Internal Publishing; 2014: 2323-40.

69. Yogiantoro M. Hypertension Clinical Approach. In: Setiati S, Alwi I, Sudoyo A, Simadibtara M, Setiyohadi B, Syam FA, editors. Internal medicine textbook. Edition 6. Jakarta: Internal Publishing; 2014: 2259-83

70. D'Ascoli, T.A., et al. "Association between serum long-chain omega-3 polyunsaturated fatty acids and cognitive performance in elderly men and women: The Kuopio Ischaemic Heart Disease Risk Factor Study." European Journal of Clinical Nutrition, 2016, 70.8: 970-975.

71. Lukaschek, Karoline, et al. Cognitive impairment is associated with a low omega-3 index in the elderly: Results from the KORA-Age study. Dementia and Geriatric Cognitive Disorders, 2016, 42.3-4: 236-245.
72. Kristiana T. Relationship Between Muscle Mass and Muscle Strength with Physical Performance in Older Age. Cross Sectional Analytical Observational Research on Elderly Community in Surabaya. 2019. Thesis. Airlangga University.

73. Pratiwi YS, Lesmana R, Setiawan S, Purba A. Literature Review: Autophagy and Sarcopenia. Syifa'MEDIKA: Journal of Medicine and Health, 2019, 10.1: 30-44.

74. Biben V, Defi IR, Suselo D. Elastic Band Training Effect to Parameters of Sarcopenia in Elderly Community-Dwelling. Global Medical \& Health Communication, 2019, 7.2: 136-142.

75. Hani, Zikra S. The Effect of Omega 3 Supplements on Serum TNF-a Levels, Muscle Mass, Muscle Strength and Physical Performance in COPD Patients with Sarcopenia. 2019. Thesis. Andalas University. 